\title{
Technological model for composing accompaniment to a melody in teaching accordion
}

\author{
Iliana Chervenakova \\ Faculty of Education, Plovdiv University P. Hilendarski, Plovdiv, Bulgaria
}

Email address:

nikolai_em2000@abv.bg

To cite this article:

Iliana Chervenakova. Technological Model for Composing Accompaniment to a Melody in Teaching Accordion. International Journal of Literature and Arts. Special Issue: Discourses of Militarization and Identity: Literature of Conflict. Vol. 2, No. 5-1, 2014, pp. 49-55. doi: $10.11648 /$ j.ijla.s.2014020501.18

\begin{abstract}
This paper is motivated by the need to optimize the conditions of active teaching, i.e. for a very short period the students must develop an ear for music and musical skills - these students are future music teachers in kindergartens and elementary schools and they must acquire basic music reading skills in playing easy plays and songs with accompaniment, learning and mastering the basic means of expression in music and in particular - polyphony, forming a sense of adequate perception and evaluation of polyphony, i.e. mastering a system necessary for practical activities. Each of these, examined separately, is directly related to the development of the sense of polyphony. The composition of elementary chord accompaniments to melodies is widely used in everyday pedagogical practice of kindergarten and elementary-school teachers and developing a purposeful pedagogical technology is of great importance for the future professional realization of students. Music classes place an special emphasis on the application and significance of music accompaniment; students are also acquainted with the prerequisites for successful work. In the referred article, the instrumental accompaniment is reviewed only for educational purposes. Building up skills for combination of such accompaniments is related to searching and finding various pedagogical approaches and technologies for the development of the sense of polyphony. The tasks are structured in a set algorithm. The presented pedagogical approaches clearly show that musical, theoretical and instrumental teaching is carried out. The transfer of knowledge and skills contributes to permanent and effective learning of the necessary theoretical knowledge and practical skills which, in its turn, helps to reach an accord between theory and practice. The system of technologies offered is comprehensive - it contains basic principles for composition of chord accompaniment as well as specific ones - applicable only for teaching accordion. The developed preliminary model of pedagogical approaches is successfully confirmed by a pedagogical experiment held with 76 students - future kindergarten and elementary-school teachers. This confirmed the purpose of the study, namely, by influencing their ear for music to teach and master in students differential perception of polyphonic music and form, on this basis, skills for composition of elementary chord accompaniments to melodies.
\end{abstract}

Keywords: Accordion, Accompaniment

\section{Introduction}

I am a lecturer at the Plovdiv University PaisiiHilendarski. My students are future kindergarten and elementary-school teachers. The future professional realization of students presupposes preparation for teaching music to children aged between 4 and 11 .

This determined the main obligations the profession imposes on the music teacher, namely:

- playing small instrumental plays intended for perception of music by children;
- playing accompaniment to easy children's songs.

As an accordion teacher for students - future music teachers for children, I found the basic principles of my pedagogical activity. While in accordion classes the students acquire the necessary skills and technical dexterity to play short and easy music plays, current practices in teaching students do not include musical accompaniment. This determined the direction of my pedagogical study. 


\section{Purpose of the Study}

The basic music activities in teaching children are performance and perception of music. Of course, perception of music is the most accessible activity. However, it will be much more efficient when, while listening carefully, various musical images accumulate in the musical memory of the child.

The richer these images are and more numerous, the more effective music perception will be and the bigger the emotional response in young listeners will be.

The most effective way to achieve this is the personal performance of music. Playing music with voice allows such careful and active perception of the melody that presupposes its following with voice, i.e. its reproduction.

This particularly active way of music production allows formation and strengthening of musical images in the mind - the basis of further enrichment of musical experience.

\section{Focus on Problems}

In view of the requirements of the profession, I directed my pedagogical work to formation of a pedagogical system of algorithms that will help students compose and play easy chord accompaniment with accordion to children's songs.

Arguments setting the directions of my pedagogical research:

- The accordion is a harmonic instrument allowing playing of accompaniment with ready chords major and minor triads and diminished major quartals. Each bass (dominant bass and bass-chord) that is considered a keynote allows unimpeded play of all three harmonic functions - T, S, D because over each bass (considered a keynote) there is a dominant and below it - a subdominant. And the skill to play neighbouring basses positioned below and above the respective bass is learned as early as the first accordion classes.

- For the successful learning of a new song by the young students, it is very important for it to be properly presented to the children from the start. It must sound in a way attracting children's attention and provoking their desire to sing the song. Of course, the children may hear the song from a record. In the record it will sound with a rich instrumental accompaniment. But the live performance of the instrumental accompaniment by the teacher is far more interesting and attractive to children. They see and hear how music is played and this, of course, provokes their desire to participate in this process.

The initial presentation of the song is performed by the music teacher - the teacher plays the song artistically, with all performance techniques, accompanying the performance with a musical instrument. The way the teacher presents the song before the young audience will determine whether it will provoke interest in children and a desire to sing it.
When a song is played with instrumental accompaniment it becomes more attractive, more interesting, more intriguing and has a more vivid influence on children.

Even the simplest children's song sounds richer and much more meaningful with accompaniment.

The role of instrumental accompaniment is very important for the pedagogical work of every music teacher because:

a) it gives stability to the intonation of the played song;

b) it keeps rhythm pulse much more easily;

c) it directs students, organizing simultaneous start, synchronizing singing and keeping a certain tempo, i.e. it has "conducting" functions;

d) it directs performers by imposing certain dynamic shades, suitable nuances and logical phrasing;

e) it contributes to a more vivid distinction of the music genre (waltz, march, etc.);

f) it gives a functional clarification, through the chord accompaniment, of the dominant tones in the music thought and this facilitates the adequate understanding of the melody logic, hence - its easier memorization;

g) it promotes emotional empathy for the music content of the performed song;

h) it facilitates the brighter perception of the performed song.

Before realizing the purpose of the pedagogical experiment we must take into account the necessity to provide the following preconditions:

- Good level of development of the music skills of the students and, in particular, the sense of polyphony that will ensure more successful composition of instrumental accompaniment;

- Knowledge of the notes of violin $(\mathrm{G})$ and bass $(\mathrm{F})$ key;

- $\quad$ Skills to find the mode-degree content of melodies;

- Skills for building the dominant triads in tonalities to 2 tones;

- $\quad$ Skills to play basses on accordion - dominant bass and chord (major and minor), and to find the two basses below and above the already performed bass;

- $\quad$ Ability to read and write down the accordion bass parts in tonalities to 2 tones;

- Familiarization with the layout of basses - from the basic $\mathrm{C}$ bass, above and below.

For provision of these conditions for successful pedagogical experiment that include introduction to music alphabet, determining the mode-degree construction of the melody, introduction to the tone content of tonalities to 2 tones, including construction of their dominant triads, I used the knowledge and skills of students acquired from subjects studied in parallel - sheet music literacy and music theory.

Playing the scales of major and minor tonalities to 2 tones with the right hand, introduction to the layout of accordion basses and their marking as well as locating the basses in the vertical second, third and fourth row is 
performed as early as the initial accordion classes, i.e. this is the traditional accordion training.

The real work of implementing the programme of my studies - composition and performance of chord accompaniments to melodies, is organized with the following specific activities and approaches, presented in their sequence.

\section{Description of the System of Pedagogical Technologies Teaching Skills for Composition of Melody Accompaniments}

My first aim was to form and develop the sense of polyphony, a basic requirement for the successful realization of my pedagogical purpose.

The sense of polyphony shows a good ear for music. "It allows differential perception of two or more simultaneously sounding voices" (2., p. 49). This shows that the sense of polyphony is a superior ability that builds on the basic musical abilities. In general, it is defined as the ability to "differentiate simultaneously sounding voices and evaluate the expressive meaning of polyphony in the specific work" (3., p. 67).

Observing these basic theoretic postulates, the tasks are developed in the following algorithm (1):

1. As early as the first accordion classes the attention of students is directed to differential perception of polyphony in harmonic intervals and triads, i.e. to individual sounding of each voice:
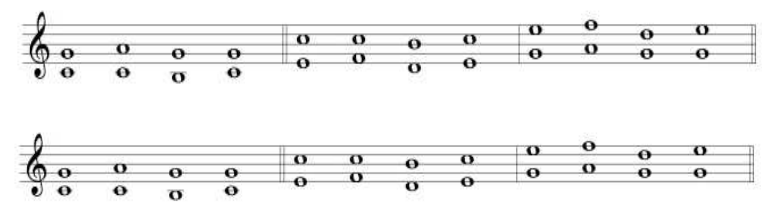

Figure 1a). Harmonic intervals

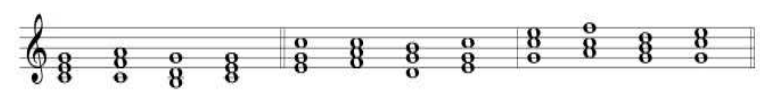

Figure 1b). Triads

As the sound of the bass is the most difficult to make, rhythmic movement of the basses is performed:

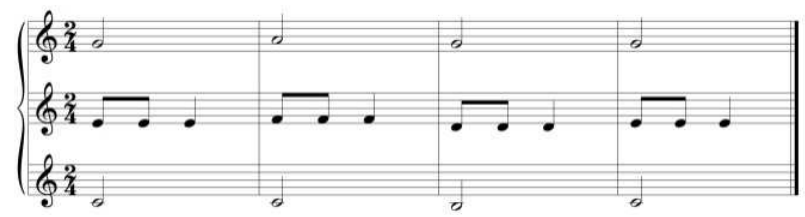

Figure 2a). Example for rhythmic movement

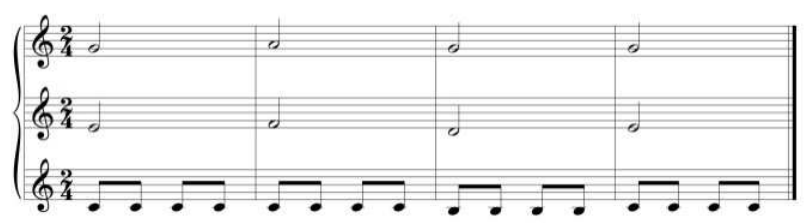

Figure $2 b$ ). Example for rhythmic movement

At the same time, students listen to a large number of melodies performed with a suitable chord accompaniment that will make it possible for them to acquire a rich sound experience for:

a) logical following of chords in harmonic accompaniment;

b) clarification of the mode-harmonic functions of melody tones through the chord accompaniment.

Along with this, with the purpose of obtaining feedback about the reliability of the sound experience of students with the illustrative role of the chord accompaniment to melodies which not only enriches but also brings diversity and emphasizes the harmonic function of each tone of the melody, the following tasks were set to students for evaluation of the accompaniment:

a) a suitable accompaniment, i.e. correct and exact perception of the logical sequence of chords;

b) emphasis on the emotional content of the melody;

c) contribution to the unmistakable detection of the genre of the accompanying melody - march, waltz, horo (Bulgarian folk dance).

In the next period of training the students will master the skill to synchronize performance with both hands - a simple melody for the right hand with a repeating tone for the left hand (over the principal bass):
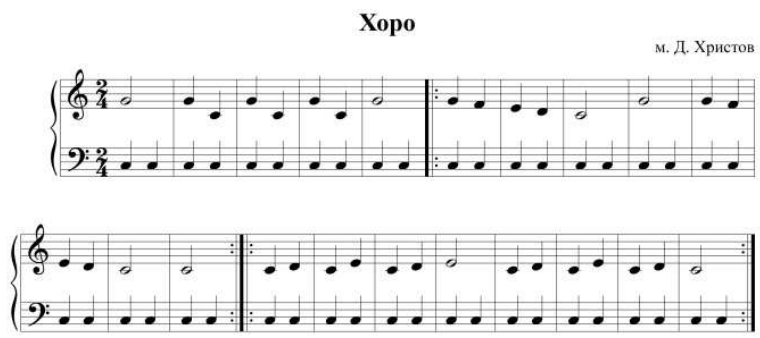

Figure 3a). Horo (Bulgarian folk dance), music: D. Hristov

The complication of the technical task comes with the slight change of the left hand part, training the performance habit of quickly finding the two principal basses located one above the other:
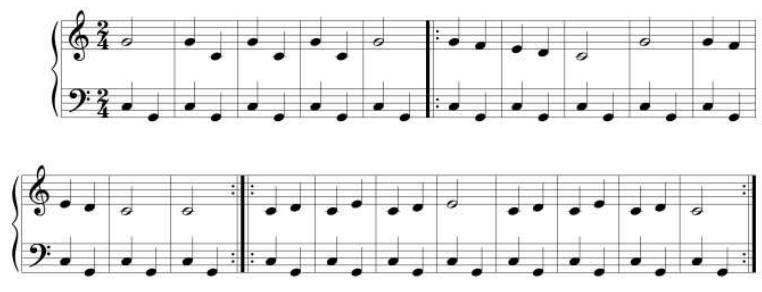

Figure $3 b$ ). The left hand part changed 
The next step allows students to master the skill of performing with the left hand a dominant bass (located on the second vertical row of basses) and a bass chord (located on the third vertical row):

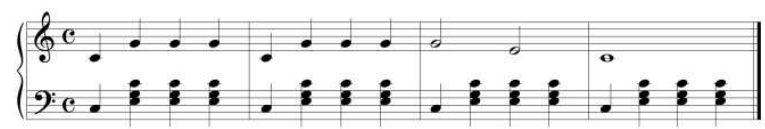

Figure 4. A dominant bass and a bass chord

Achieving this skill allows the use of the two basic functions of harmonic accompaniment $-\mathrm{T}$ and $\mathrm{D}$ :

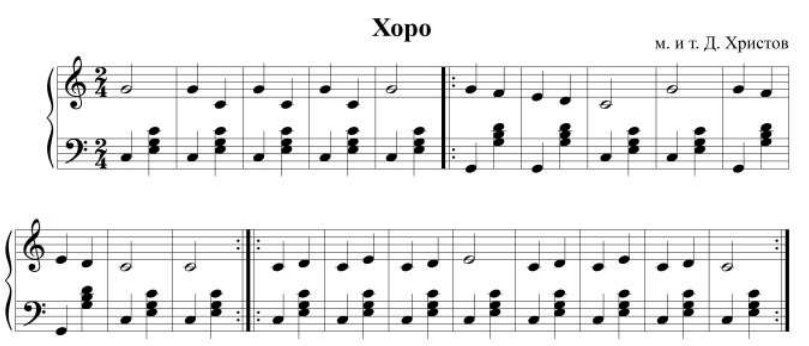

Figure 5. Horo (Bulgarian folk dance), music and text: D.Hristov

The same skill is acquired by performing melodies in triple metre:

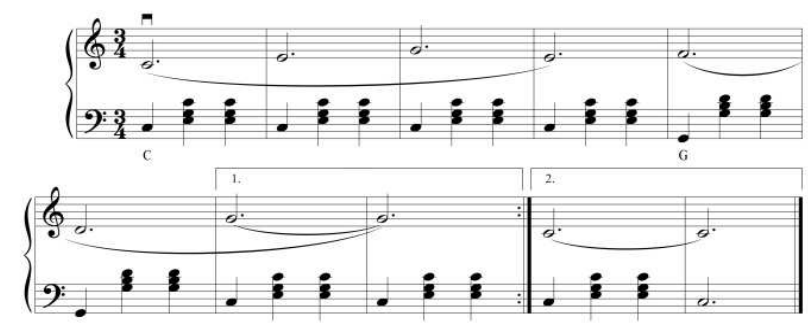

Figure 6. Melody in triple metre

Subdominant function (S) appears in the accompaniment during the next lessons:
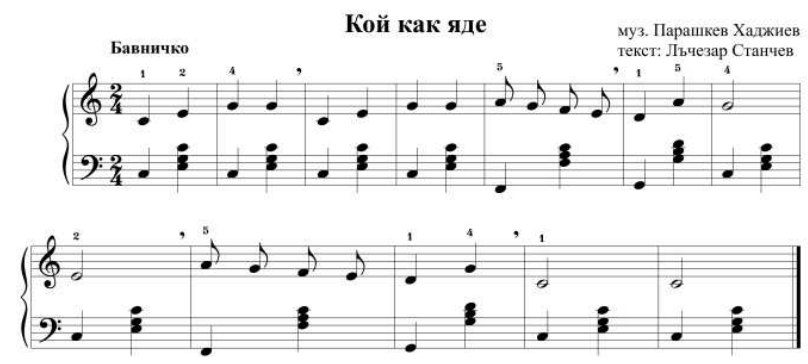

Figure 7. Song (music: ParashkevHadzhiev, text: LachezarStanchev, song title: How Everybody Eats) slowly

Ensuring the abovementioned technical skills in students allows transition to the real activity of composition of harmonic accompaniment. It presupposes the following algorithms:

After determining the tonality of the melody, its modedegree structure will be determined, too:

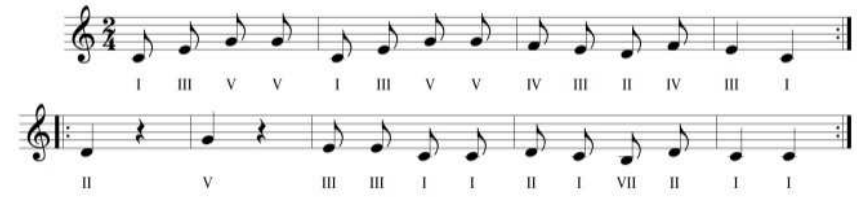

Figure 8. Mode-degree structure of the melody of Figure 7

The next logical task is to find to which of the three main triads mode degrees in each bar belongs.

In this case, the first, second, fourth, seventh and ninth bars have a tonic function and the third, fifth, sixth and eighth bar dominant function, but we will clarify that the fourth mode degree is included in the dominant septachord (D7). This must be observed, analyzed, listened to and performed by students.



Figure 9. Song (music: P. Stupel, text: G. Avgarski, cheerfull,y song title: The Watch)

The necessary information the students must obtain in order to choose the proper chords for composition of chord accompaniment is the following: it is recommended to use the same chord within the same bar; the melody must finish with a tonic function (T); most often it is preceded by the dominant function (D); the proper chords below the musical score may be marked with letter designations $-\mathrm{C} \mathrm{c}$ - for bass C, G g - for bass G, etc., or with the functional meaning of the chords; it is recommended for the students to use both means:

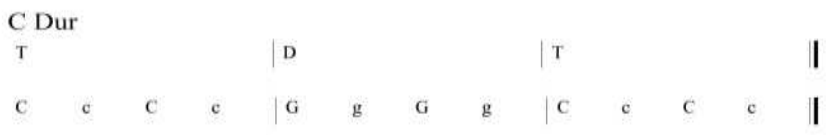

Figure 10. Chords of the song of figure 9 marked with letter designations

(The designation of harmonic functions allows the easier transposition of the harmonic accompaniment and the melody in the next classes.)

This is followed by the real task of composition of chord accompaniment or harmonization of a melody with simple harmonic means. 


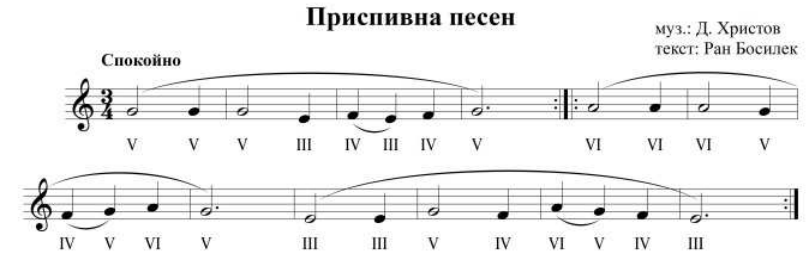

Figure 11. A song (music: D. Hristov, text: Ran Bosilek, calmly, song title: Lullaby)

The functions are determined after the mode-degree analysis:

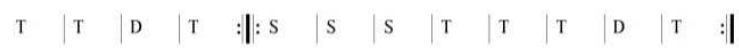

Figure 12. Mode functions of the song of Figure 11

In the fifth bar there is a clearly distinguished $\mathrm{S}$ function and in the penultimate bar, with the sequence of VI, V and IV degrees in the melody, we use D function that precedes $\mathrm{T}$.

We must clarify that in the performance of the accompaniment the song is in $3 / 4$ and after the performance of the principal bass the chord will sound two times, i.e. the bass button representing the major chord - $\mathrm{C}$ cc, etc., will be pressed two times.

After mastering initial dexterity with the right hand, the sequence T S D T should be performed without problems with the left hand and after that with both hands.

The next explanations refer to the participation external of tones in the melody that must be harmonized - tones that decorate the melody, appear in a weak metric time and are not included in the structure of the specific chord:
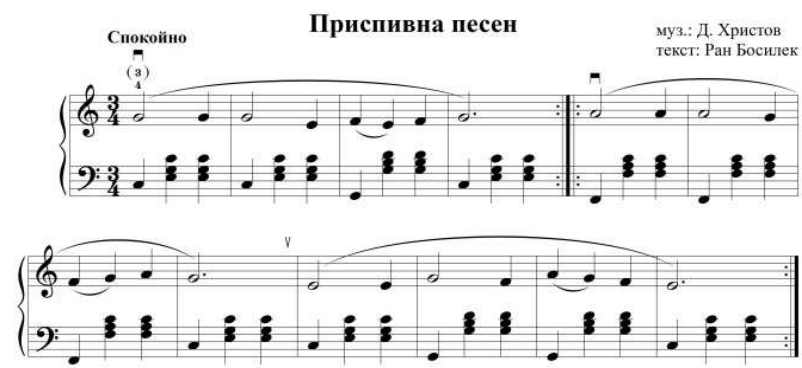

Figure 13. Song (music: D. Hristov, text: Ran Bosilek, calmly,song title: Lullaby)

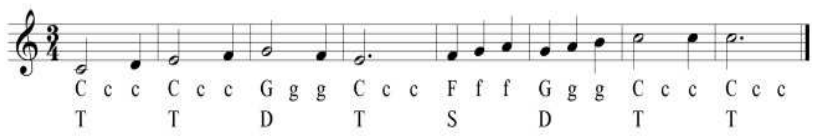

Figure 14. Chords marked with letter designations

The students had no difficulties in composing a proper chord accompaniment to the following melody:

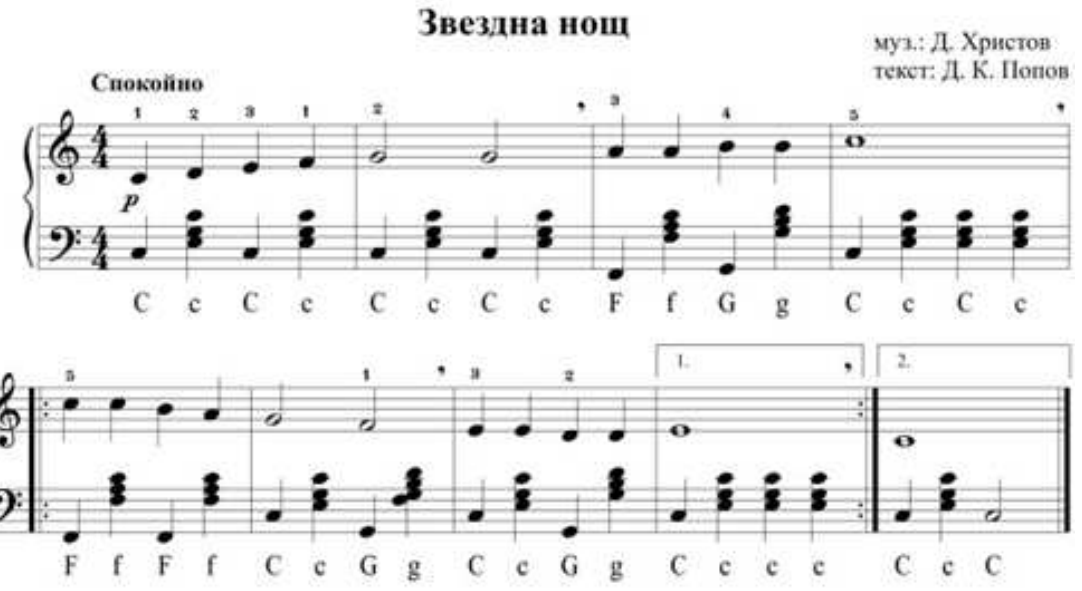

Figure 15. Song (music: D. Hristov, text: D. K. Popov, calmly, song title: Starry Night)

With the next melody, the skill to harmonize melodies in minor modes was mastered. (In the left part of the accordion, the fourth vertical row of basses is used). This bass is marked by the additional letter " $\mathrm{m}$ " to the letter designating the chord $(\mathrm{C} \mathrm{cm})$.

So far, this work presented a system of technologies for composition of a simple accompaniment for teaching purposes - doubling of the melody with the right hand and functional accompaniment with main triads $(T, S, D)$ in the left hand.

In artistic accompaniment, the ability of the music teacher to compose a proper prelude to the played song, is of great importance too. It will allow: mode orientation, mode setting, use of proper tempo, nuances, dynamics, etc.
The prelude can include motives of the very song, a new similar proper melody can be composed (for more gifted students) or two bars can be performed only with the accordion basses, introducing tempo, rhythm, tonality and dynamics.

Listening was an important criterion for evaluation of the composed accompaniment and the indicators showed the following:

- It sounded well, the chords suited the melody;

- The accompaniment enriched and complemented the song;

- The accompaniment facilitated understanding the emotional content of the melody.

At the end of the teaching period the students performed 
an accompaniment of the following type, including prelude to the song and movement in parallel major thirds and major sixths with the right hand that enriched the melody.



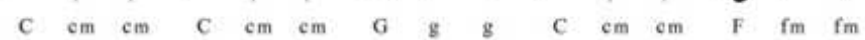
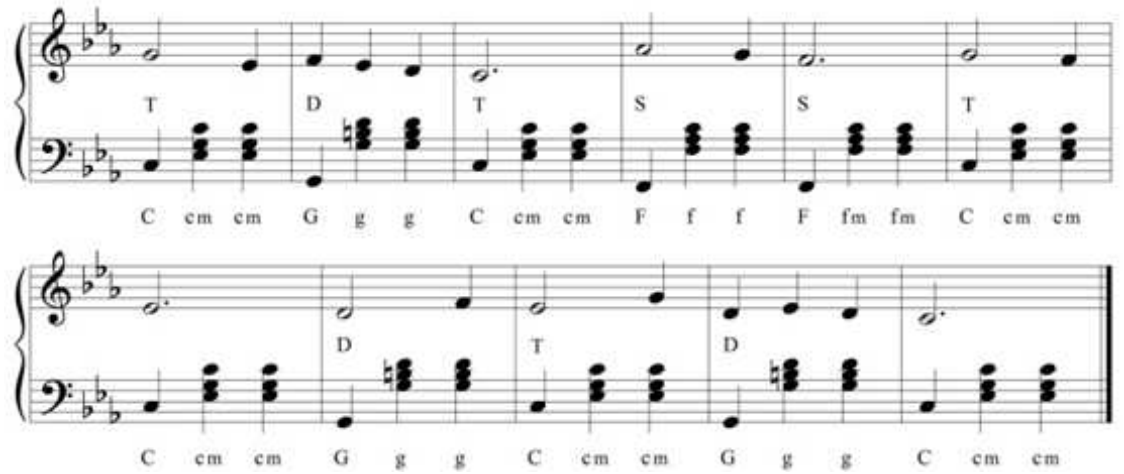

Figure 16. Additional letter " $m$ " for marking the minor mode
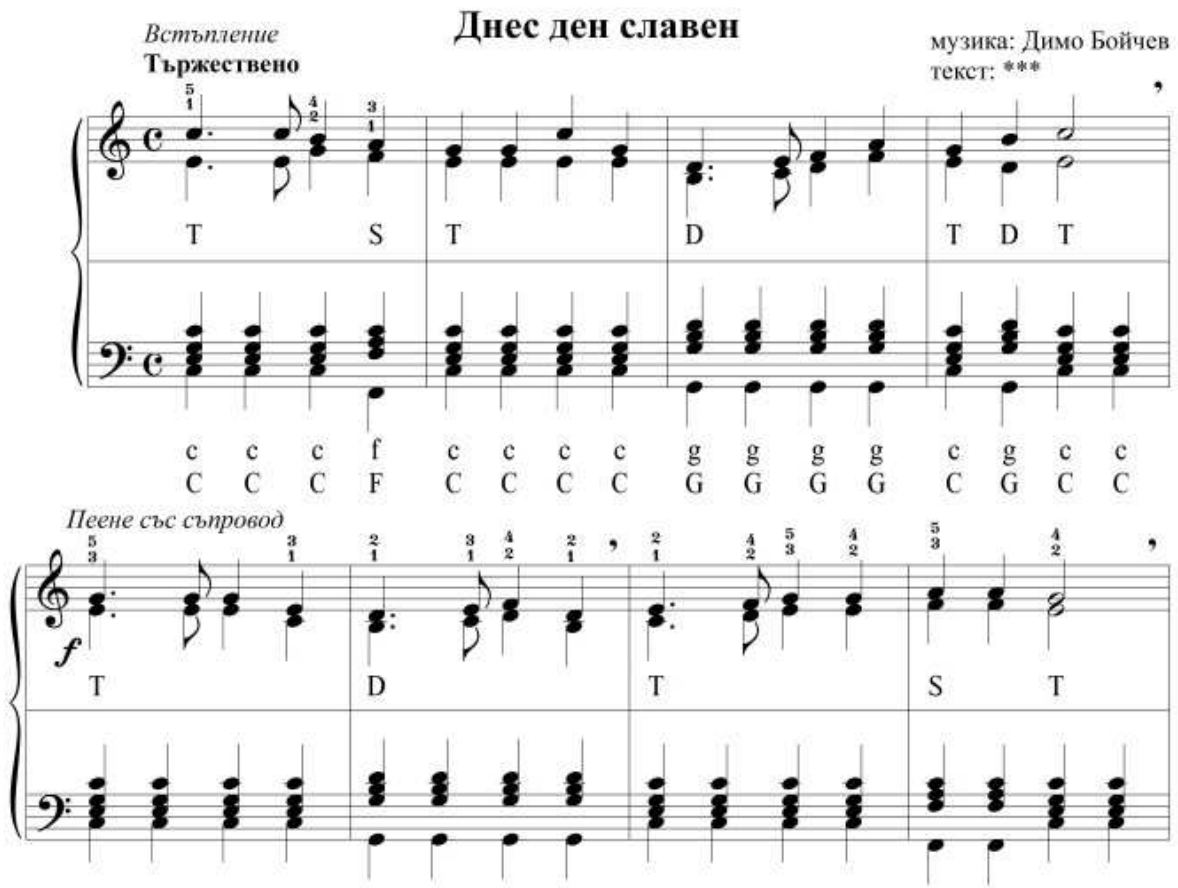

$\begin{array}{llllllllllllllll}\mathrm{c} & \mathrm{c} & \mathrm{c} & \mathrm{c} & \mathrm{g} & \mathrm{g} & \mathrm{g} & \mathrm{g} & \mathrm{c} & \mathrm{c} & \mathrm{c} & \mathrm{c} & \mathrm{f} & \mathrm{f} & \mathrm{c} & \mathrm{c} \\ \mathrm{C} & \mathrm{C} & \mathrm{C} & \mathrm{C} & \mathrm{G} & \mathrm{G} & \mathrm{G} & \mathrm{G} & \mathrm{C} & \mathrm{C} & \mathrm{C} & \mathrm{C} & \mathrm{F} & \mathrm{F} & \mathrm{C} & \mathrm{C}\end{array}$

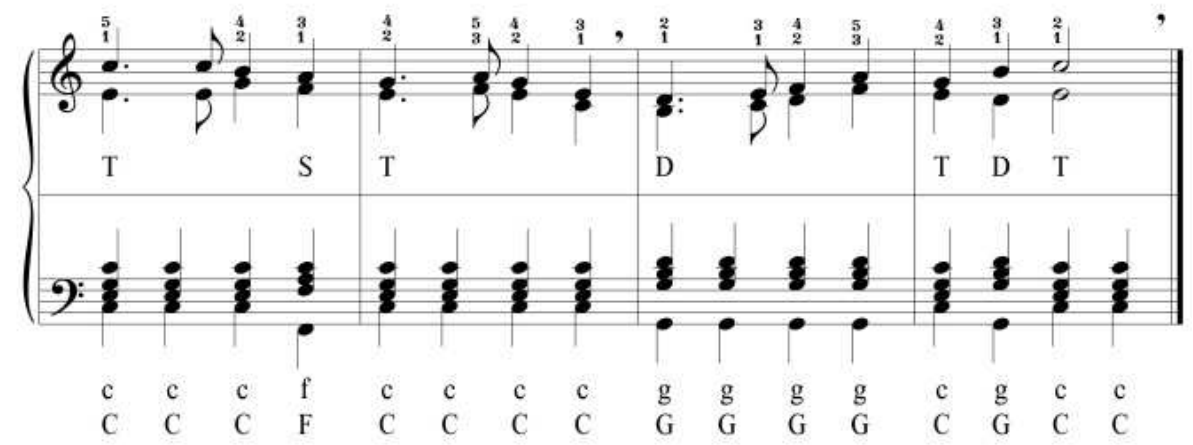

Figure 17. Song (music: DimoBoychev, text: ***, prelude, solemnly, song title: Today, A Glorious Day) singing with accompaniment 
The students always faced problematic situations that had to be solved. So, this was an active training, focused on the pedagogical practice of the music teacher.

\section{Conclusion}

By acquiring theoretical knowledge together with practical skills, unity was achieved between theory and practice.

Different learning techniques were mastered that facilitated the acquisition of the necessary knowledge and skills for professional realization of the students - future kindergarten and elementary-school teachers.

The system of technologies offered is comprehensive - it contains basic principles of composition of chord accompaniment, as well specific ones - applicable only for accordion training.

The preliminary developed model of pedagogical approaches was successfully confirmed by the pedagogical experiment held, thus achieving the purpose of the study, namely, by influencing the ear for music, to train and develop in students the ability for differential perception of polyphonic music and on this basis to form skills for composition of simple chord accompaniments.

So the instrumental accompaniment must be studied in depth and with precision by the students - future kindergarten and elementary-school teachers.

\section{References}

[1] Chervenakova I, Dissertation: "Technologies of Composition of Simple Chord Accompaniment to a Melody" (with students majoring in Preschool Pedagogy with Foreign Language and Elementary-school Pedagogy with Foreign Language). Plovdiv, 2013. (Червенакова, И.,Дисертация:,Технологии за изработване на елементарен акордов съпровод към мелодия"(със студенти от специалностите „Предучилищна педагогика и чужд език” и „Начална училищна педагогика и чужд език”). Пловдив, 2013)

[2] Mincheva P. Methods of Solfège Training. Plovdiv, 2006. (Минчева, П. Методика на обучението по солфеж, Пловдив, 2006)

[3] Mincheva P. Music Education in Comprehensive Schools. Sofia, 1994. (Минчева П. Музикалното възпитание в общообразователното училище. София, 1994) 